\title{
Ocular Co-morbidity in Patients with Refractive Errors in Nigeria
}

\author{
BO Adegbehingbe FWACs, O Adeoye FWACs, BA Adewara mbBs \\ Ophthalmology Unit, Faculty of Clinical Sciences, Obafemi A wolowo University, Ile-Ife
}

\section{ABSTRACT}

Purpose: To determine the pattern and prevalence of other ocular problems seen in patients with refractive errors in a Nigerian teaching hospital.

Methods: A retrospective hospital-based review of all consecutive patients who presented with signs and symptoms of refractive errors at the Obafemi Aw olow o University Teaching Hospitals Complex between $1^{\text {st }}$ January 2007 and $31^{\text {st }}$ August 2007. Patients who had a diagnosis of refractive error and subsequently had detailed eye examination were included in this study. Data was retrieved from the patients' clinical records and analyzed with SPSS version 15.

Results: Out of 724 new patients seen within the study period, 235 had refractive errors $(93$ males and 142 females). Patients' ages ranged between 7 and 74 years with a mean of $30.5+/-4.6$ years. In more than half (54\%) of the patients, associated ocular co-morbidities were documented. The vision-impairing diseases documented morbidities in 56 (44.1) patients were cataract $26(20.5 \%)$, glaucoma $20(15.8 \%)$, diabetic macu lop athy $3(2.7 \%)$, am blyopia, corneal op acities and CMV retinitis. Non vision-impairing disorders documented were conjunctivitis, 49 (38.6\%); p terygium $6(4.7 \%)$, chalazion $5(3.9 \%)$, hypertensive retinop athy 4 $(3.1 \%)$, dry eyes and ep iscleritis. Imm ature cataract w as responsible for about $2 / 3$ of cases with poor corrected visual acuity documented in a large proportion of the patients $26(11.1 \%)$.

Conclusion: Patients with refractive errors need detailed ocular examination for early detection of other comorbidities which may significantly affect vision and lead to avoidable blindness and visual impairment.

Key words: refractive errors, ocular co-morbidity, glaucoma, visual impairment, blind ness

\section{INTRODUCTION}

Refractive errors (myopia, hyperm etropia, astigm atism and presbyopia) affect a large proportion of people of all ages and gender. Patients with refractive errors (RE) account for a high proportion of patients atten ding ophthalmic clinics..$^{1-4}$ Refractive errors can be easily diagnosed, measured and corrected with spectacles or other refractive corrections to attain normal vision. How ever, non correction or in ad equate correction of refractive errors becomes a major cause of low vision and even blindness. Globally, there are 8 million people who are blind and 153 million with visual impairment (presenting visual acuity $<6 / 18$ in the better eye) due to uncorrected refractive errors; this excludes presbyopia. ${ }^{5}$ Poor visual outcome in patients with refractive errors could be in part due to other associated ocular morbidity, though some patients with co-existing ocular morbidity may still attain normal vision.

Studies by various researchers have shown relationships between refractive error and other ocular morbidities such as cataract, ${ }^{6}$, glau coma ${ }^{7}$ and allergic conjunctivitis. ${ }^{8}$ Detailed assessments of individuals who have refractive errors provide an opportunity for identifying other potentially coexisting blinding conditions before they cause visual loss. The consultation of 'road-side dispensers' by most patients in developing countries and lack of detailed ocular examination by optometrists and opticians in these communities has remained one of the main challenges to the correction of refractive errors and possible identification of other co-morbidities. The majority of patients also circumvent the services of eye care professionals and consult non-qualified personnel for a number of reasons, including the belief of 'cost savings'. ' Patients in these categories will automatically miss detailed and comprehensive review by ophthalmologists and as such, some asymptomatic ocular conditions such as glaucoma (a major cau se of irreversible blind ness) may not be diagnosed early enough for prompt treatment. It has been well documented that patients who require frequent change of spectacles may actually be suffering from other ocular diseases, especially glau coma.

This study was undertaken to assess the frequency of patients that seemingly present with refractive errors but actually have other eye diseases. The aim was to determine the pattern and prevalence of other ocular co-morbidities such as glaucoma, ocular hypertension, cataract, hypertensive retinopathy, diabetic retinopathy, and other eye disorders in patients with refractive error in a tertiary eye care centre. This will assist in providing information

Correspondence: Dr Bernice O Ad egbehingbe, Ophthalm ology Unit, Department of Surgery, Faculty of Clinical Sciences, Obafem i Aw olow o University, Ile-Ife • E-mail: berniceola2003@yahoo.co.uk 
which can be useful for early detection of eye diseases and eye health planning

\section{METHODOLOGY}

A retrospective non-comparative hospital-based review of all consecutive patients who had primary diagnosis as refractive error at the Obafemi Awolowo University Teaching Hospitals Complex between $1^{\text {st }}$ January 2007 and $31^{\text {st }}$ August 2007 w as conducted. The protocol for this study was approved by the hospital research and ethics committee.

Inclusion criteria comprised patients of all ages who presented with vision of $\leq \mathrm{N} 8$ for near or $\leq 6 / 12$ for distance. Distant visual acuity in all subjects was improved with a Pin Hole and refraction by at least two lines on the Snellen's chart. Included in this study were patients in whom refractive errors were associated with other ocular or systemic disease such as cataract, glaucoma, corneal scars, diabetes, maculopathy, keratoconus, chalazion, marginal corneal degenerations, pterygium or previous ocular surgery or drugs that could cause shifts in refractive error.. Excluded from the study were those patients who had no improvement in their visual acuity with refraction.

Data collected on the patients included demographics such as patients' age, sex, occupation and level of education. Others were presenting ocular symptoms and signs, presenting visual acuity (with or without Pin Hole test), drug and past medical history. Intraocular pressure, dilated fund uscopy and detailed eye exam inations were carried out by a consultant ophthalmologist. Refraction measured with retinoscopy accompanied with subjective testing was done by an optometrist.

Glaucoma damage was defined as reproducible glaucomatous visual field defects with the Humphrey Full Threshold 24-2 programme with or without elevated intraocular pressure in association with characteristic op tic nerve head damage. Gonioscopy was done on those who had glau coma to determ ine the status of anterior chamber angle; those with elevated IOP in the presence of an open angle were diagnosed as having primary open angle glaucoma.

Cataract was diagnosed and classified based on slit lamp assessment. In cases where a patient had co-morbidity in both eyes, the eye with the worse vision or more advanced co-morbidity was chosen for the purpose of analysis in this study. Some patients had more than one comorbidity in the studied eye; in such cases, all the problems identified were documented and analyzed. After refraction, the visual acuity of the studied eye was documented and analyzed.

Visual field test was done by trained optometrists while the results were interpreted by a consultant oph thalmologist who was the principal investigator. All patients had prescription glasses, including reading glasses dispensed as appropriate, and those in which other ocular morbidities were diagnosed were managed ap propriately. Som e of these were reviewed during their follow-up visit.
Data was imputed and analyzed using the SPSS version 15. The mean and stand ard deviations (SD) for patients' age were calculated. Variables were related using chi square and tests for statistical significance were done u sing the Welch's $t$ test. A $P$ value of less than $0.05 \mathrm{w}$ as considered significant.

\section{RESULTS}

A total of 724 new patients were seen over the study period. Of these $235(32.5 \%)$ had a primary diagnosis of refractive errors. Patients' ages ranged between $7-74 \mathrm{yrs}$ with a mean of $30.5 \pm 4.6$ yrs. A largest number of patients, $120(51.1 \%)$, were between ages 10 and 30 years, while 57 (24.3\%) were children $(</=16 y r s)$. There were 142 patients below the age of 40 years while 93 were over 40 years. There were more females, $142(60.4 \%)$ than males. Age range and sex distribution of patients with refractive errors were as depicted in table 1 .

Table 1. Sex and age range of patients with refractive errors

\begin{tabular}{lrcr}
\hline \multirow{2}{*}{ Age Range } & \multicolumn{2}{c}{ Sex } & Total (\%) \\
\cline { 2 - 3 } & Male (\%) & Female (\%) & \\
\hline $1-9$ & $5(2.1)$ & $4(1.7)$ & $9(3.8)$ \\
$10-19$ & $19(8.1)$ & $40(17.0)$ & $59(25.1)$ \\
$20-29$ & $26(11.1)$ & $35(14.9)$ & $61(26.0)$ \\
$30-39$ & $4(1.7)$ & $9(3.8)$ & $13(5.5)$ \\
$40-49$ & $12(5.1)$ & $26(11.1)$ & $38(16.2)$ \\
$50-59$ & $14(6.0)$ & $15(6.4)$ & $29(12.4)$ \\
$60-69$ & $11(4.6)$ & $10(4.3)$ & $21(8.9)$ \\
$70-79$ & $2(0.8)$ & $3(1.3)$ & $5(2.1)$ \\
Total & $93(39.5)$ & $142(60.5)$ & $235(100)$ \\
\hline
\end{tabular}

More than half of the patients, 127 (54\%) had other associated causes of ocular co-morbidity (table 2). Visionimpairing diseases documented co-morbidities in $56(44.1)$ patients were cataract $26(20.5 \%)$, glaucoma $20(15.8 \%)$, diabetic maculopathy $3(2.7 \%)$ and others 7 (5.5\%) such as amblyopia, corneal op acities and CMV retinitis. Non visionimpairing disorders documented were conjunctivitis, 49 $(38.6 \%)$; pterygium $6(4.7 \%)$, chalazion $5 \quad(3.9 \%)$, hypertensive retinopathy $4(3.1 \%)$ and others $7(5.5 \%)$ such as dry eyes and episcleritis. Immature cataract was responsible for about $2 / 3$ of cases with poor corrected visual acuity documented in a significant proportion of the patients $26(11.1 \%)$. The most common ocular co-morbidity in patients below 40 years of age was allergic conjunctivitis $(12.4 \%)$, while cataract and glau com a $(16.2 \%)$ w ere the more prevalent in those above 40 years. This distribution of ocu lar co-morbidity in relation to patients' age was statistically significant, $P=0.0001$. There were 4 individuals with double co-morbidities, two had co-existing glaucoma and cataract while 2 had pterygium and cataract. Cataract was significantly associated with age, $P=0.0001$. 
Table 2. Age range and ocular co-morbidity in 127 patients with refractive errors.

\begin{tabular}{|c|c|c|c|c|c|c|c|c|c|c|}
\hline \multirow{2}{*}{$\begin{array}{l}\text { Age } \\
\text { range }\end{array}$} & \multicolumn{10}{|c|}{ Disease condition in the worse eye } \\
\hline & $\begin{array}{c}\text { Allergic } \\
\text { Conjunctivitis }\end{array}$ & Cataract & Glau coma & $\begin{array}{c}\text { Diabetic } \\
\text { Retinopathy }\end{array}$ & $\begin{array}{l}\text { Age Related } \\
\text { maculopathy }\end{array}$ & Amblyopia & Hypertension & pterygium & Others & Total \\
\hline $0-9$ & 2 & & 0 & 0 & 0 & & 0 & 0 & 1 & 3 \\
\hline $10-19$ & 11 & & 2 & 0 & 0 & 1 & 0 & 0 & 2 & 16 \\
\hline $20-29$ & 16 & 0 & 2 & 0 & 0 & 2 & 0 & 0 & 10 & 30 \\
\hline $30-39$ & 1 & 4 & 0 & 1 & 0 & 0 & 0 & 0 & 1 & 7 \\
\hline $40-49$ & 8 & 4 & 5 & 2 & 0 & 0 & 0 & 2 & 4 & 25 \\
\hline $50-59$ & 8 & 3 & 6 & 1 & 1 & 0 & 2 & 2 & 3 & 26 \\
\hline $60-69$ & 3 & 5 & 4 & 0 & 2 & 0 & 1 & 1 & 3 & 19 \\
\hline $70-79$ & 0 & 0 & 1 & 0 & 1 & 0 & 1 & 1 & 1 & 5 \\
\hline Total & 49 & 16 & 20 & 4 & 4 & 3 & 4 & 6 & 25 & 131 \\
\hline
\end{tabular}

The overall prevalence of cataract (excluding aphakia) was found to be four times more common in those above 40 years of age. Bilateral cataract w as present in $80 \%$ of patients with cataract, while the rest had unilateral cataract. Among those with glaucoma, 5 had normal tension glaucoma, 2 had juvenile open angle glaucoma while the rest had primary open angle glaucoma.

The distribution of the study population according to 'presenting' and 'best corrected' visual acuity in the better eye is show $n$ in table 3 . The overall prevalence of normal vision $(\mathrm{V} \geq 6 / 12)$, moderate visual impairment (VA $<6 / 18$ $6 / 60)$, severe visual impairment $(<6 / 60-3 / 60)$ and blind ness $(<3 / 60)$ based on 'p resenting' visual acu ity (vision with glasses if normally worn, otherw ise without glasses) w as $27.7 \%, 65.1 \%, 5.1 \%$, and $2.1 \%$, respectively. How ever based on 'best corrected' visual acuity, the prevalence rates became $88.9,10.2,0.9$ and $0 \%$ respectively.

Table 3. Distribution of visual acuity before and after refraction

\begin{tabular}{lcc}
\hline Visual & \multicolumn{2}{c}{ Frequency $(\%)$} \\
\cline { 2 - 3 } Acuity & Pre-refraction & Post-refraction \\
\hline $26 / 12$ & $65(27.7 \%)$ & $209(88.9 \%)$ \\
$6 / 18-6 / 60$ & $153(65.1 \%)$ & $24(10.2 \%)$ \\
$<6 / 60-3 / 60$ & $12(5.1 \%)$ & $2(0.9 \%)$ \\
$<3 / 60$ & $5(2.1 \%)$ & - \\
Total & $235(100 \%)$ & $235(100 \%)$ \\
\hline
\end{tabular}

Aetiology of visual impairment among the 26 patients with best corrected visual acuity $<6 / 18$ in the better eye post-refraction was as shown in figure 1. Cataract was responsible for most cases of visual impairment 17 (65.4\%); this finding was statistically significant, $P=0.002$. Eleven $(64.7 \%)$ of these were posterior sub-cap sular cataract while the others were mixed nuclear sclerosis and sub-capsular opacities.

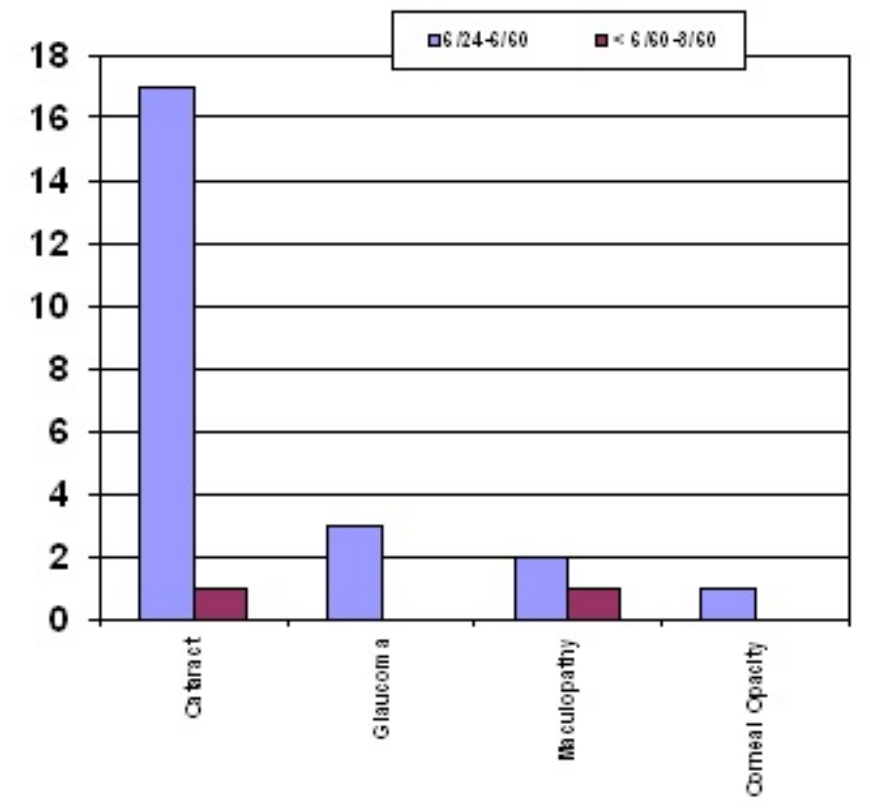

Figure 1. Ocular co-morbidity in 26 patients with visual impairment post-refraction (VA $<6 / 18$ )

Figure $2 \mathrm{a}$ and $2 \mathrm{~b}$ depict the distribution of distance refractive errors in those below and above age 40 years respectively. The most common refractive error in patients under 40 years was myopic astigmatism $60(42.5 \%)$. Others were hypermetropia $40(28.5 \%)$, myopia $23(16.2 \%)$, and hyperm tropic astigmatism $19(12.8 \%)$, only 5 patient in this age group needed distance correction. Hypermetropia was the com monest refractive error in those over 40 years. About $90 \%, 84$ of those above 40 years had presbyopia, 34 of these had no other distance refractive error. 


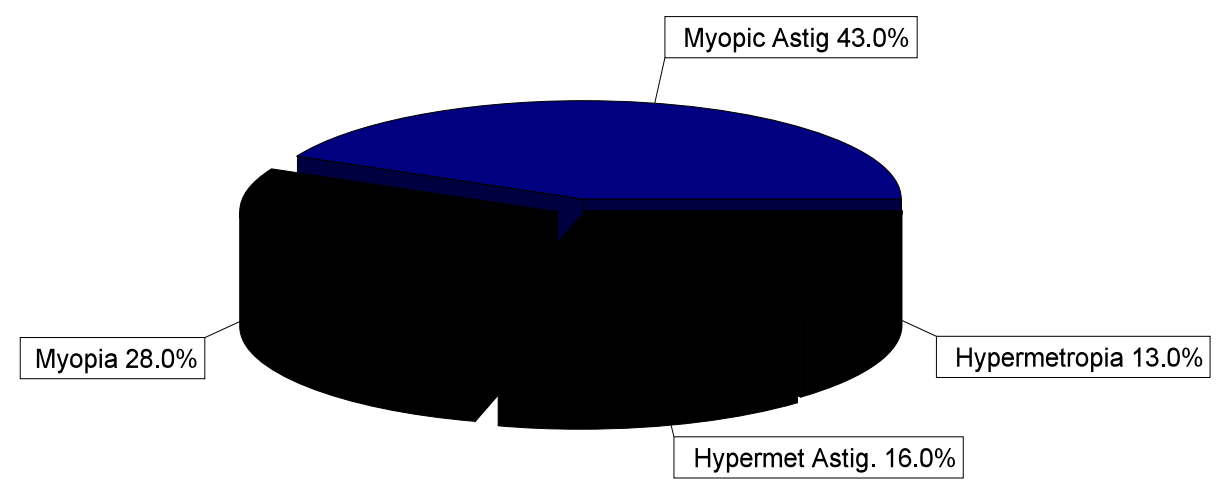

Figure 2a. Distribution of distance refractive errors in patients $<40$ years

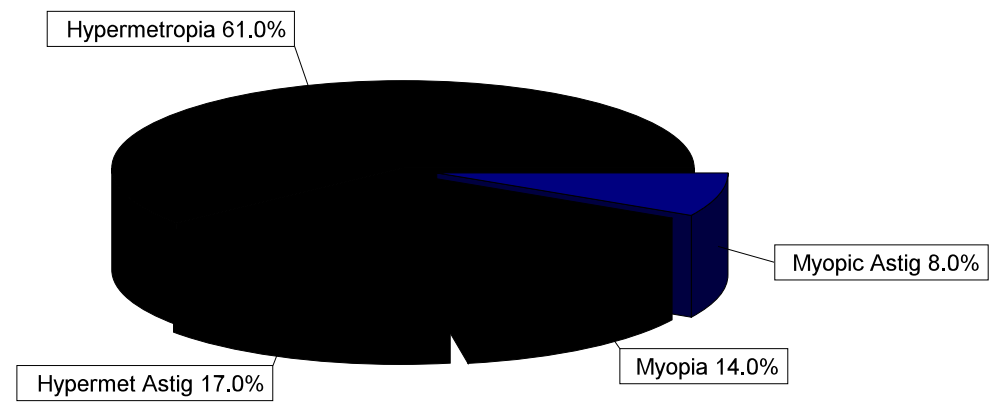

Figure 2b. Distribution of distance refractive errors in 59 patients $>40$ years

There was no significant association between hypermetropia and any of the ocular co-morbidities but myopia was significantly associated with presence of cataract $(\mathrm{P}=0.01)$, glaucoma $(\mathrm{P}=0.02)$ and keratoconus $(0.01)$.

\section{ISCUSSION}

This study analyzed the ocu lar co-morbidity and the relative frequency and magnitude of these in patients with refractive errors in, and the effect of refraction on eventual visual outcome of the patients. It revealed that there is a high prevalence of other blinding ocular problems such as cataract and glaucoma in the study population, all of which are treatable or preventable. Previous studies have shown that refractive error coexists with other ocular co-m orbidities such as allergic conjunctivitis ${ }^{8}$, cataract $^{6,10}$ and glau coma. ${ }^{7,11}$.

There is paucity of data on the prevalence of ocular morbidities found coexisting in patients presenting with refractive errors in Nigeria. This study is therefore relevant because as more people seek for glasses to address their eye problems, co-morbidities may be identified and treated to prevent visual impairment and blindness.
Reports from clinic-based study on refractive errors both in Africa and in the Western world are very few.$^{1-12}$ Though community-based studies on pattern and associated comorbidity of refractive errors have been conducted in several studies in the past, ${ }^{11-17}$ there have been very few reports of ocular co-morbidity in patients with refractive errors in hospital-based studies, ${ }^{1-4}$ hence attempts were made to find out whether the pattern of ocular co-morbidity at the community were different from that of the hospital setup.

In this study more than half of patients with refractive errors had ocular co-morbid conditions, some of which are potentially blinding. The main ocular disorder responsible for visual impairment and low vision in the study population were cataract, glaucoma, maculopathy, corneal opacity and keratoconus. Allergic conjunctivitis was the most prevalent co-morbid condition in all the patients studied. This correlates to the study done by Mimura et al. ${ }^{8}$ In developing countries such as Nigeria, allergic conjunctivitis has been found to be an important association or risk factor in patients w ith refractive errors. ${ }^{4,9}$ Som etimes, 
delayed or improper treatment of allergic conjunctivitis such as the use of harmful traditional medication, especially in resource-limited communities like in Nigeria, can have serious visual consequences. None of the patients studied had visual impairment from allergic conjunctivitis.

Next to allergic conjunctivitis, cataract and glaucoma were the most prevalent ocular disorders found in patients with refractive errors aged 40 years and above. This is similar to global statistics. Cataract was significantly associated with age in this study with more than $80 \%$ of the cases presenting in patient above 40 years of age. Similar cataract prevalence rates have been reported by several studies in Ind ia ${ }^{12,13}$ despite the fact that they are population based studies. Low er prevalence rates have, however, been reported from a few other population based studies ${ }^{14,15}$ including the Aravind Comprehensive Eye Survey where the prevalence of cataract in those aged 40 years and above was found to be $47.5 \%{ }^{16} \quad$ This difference in prevalence rate may be due to difference in sample size and study population. Also, the close association of cataract with increasing age has been documented by other studies. ${ }^{17-20}$ Two patients with posterior sub-capsular cataract were not improved beyond 6/ 18 with refraction and this contributed to the a significant visual impairm ent recorded in the study population.

The prevalence of glaucoma in the present study $(15.8 \%)$ was much higher than that reported by several Indian studies where prevalence rates ranging from $2.6 \%$ to $7.2 \%$ had been documented.$^{21-22}$ This was not unexpected as there were usually higher rates in population-based studies than in clinic-based studies. Eighty per cent of patients with glaucoma were aged above 40 years; however, prevalence rate increased with age from $1.7 \%$ in those below 40 years to $6.8 \%$ in those above 40 years. Glaucoma remains a challenging disease and has been described as a 'silent thief of sight' responsible for a significant proportion of irreversible blindness worldwide. The burden of blindness from this condition can be reduced by early diagnosis and prompt treatment. Majority of patients with glau coma in the developing world present late due to the asymptomatic nature of the disease. Routine screening of all patients who present to the eye clinic with symptoms of other eye disorders such as refractive error will serve as a means of early diagnosis and prompt treatment of glaucoma.

The prevalence of corneal opacity was lower in this study population when compared to reports from other studies. ${ }^{12,23}$ Higher prevalence rates have been documented in population studies among rural dw ellers in Nigeria ${ }^{24}$ and in East Africa. ${ }^{25}$ Ocular trauma and corneal ulcer were responsible for the few cases of corneal op acity documented.

Other causes of ocular morbidity in these patients were diabetic, hypertensive and CMV retinopathy. CMV retinopathy was seen in a patient with HIV/ AIDS who had not been diagnosed before presenting to the ophthalmologist.

In conclusion, patients with refractive error need detailed ocular examination for identification of other comorbid conditions needing care or which may affect visual prognosis. Detailed assessment of individuals who have refractive error, particu larly those aged 40 years and above, are highly desirable as this provides an opportunity for identifying and treating other potentially blinding ocular conditions such as glaucoma. Findings from this study will help to underscore the priorities for eye care services based on evidence-based data on associated co-morbidities. Health education programmes should target older age groups specifically and the population in general. Affordable eye care services should be provided in addition to making these services more readily available and accessible.

\section{REFERENCES}

1. Olurin O. refractive errors in Nigeria (A hospital clinic study). Ann Ophthalmol 1973; 5: 971-976.

2. Nworah PB, Ezepue UF. Prevalence of errors of refraction in a Nigerian eye clinic. Orient Journal of Medicine 1992; 4: 57-60.

3. Adefule-Ositelu AO. Refractive errors in Lagos, Nigeria. Nig Med J1995; 29 (3): 101-163.

4. Adegbehingbe BO, Majekodunmi AA, Akinsola FB, Soetan EO. Pattern of refractive errors at Obafemi Aw olowo University Teaching Hospital, Ile-Ife, Nigeria. Nigerian Journal of Ophthalmology 2003: 11(2): 76-79.

5. Resnikoff $\mathrm{S}$ et al. Global magnitude of visual impairment cause by uncorrected refractive error in 2004. Bulletin of the WHO Jan 2008; 86:63 - 70 .

6. Amruta SP, Khandekar R, Dharmadhikari S, Dole K, Gogate P, Deshpande M. Prevalence of uncorrected refractive error and other eye problems among urban and rural school children. Middle East Afr J Ophthalmol 2009 Apr-Jun; 16(2): 69-74.

7. Krishnaiah S, Srinivas M, Khanna RC, Rao GN. Prevalence and risk factors for refractive errors in the South Indian adult population: The Andhra Pradesh Eye Disease Study. Clin Ophthalmol 2009; 3: 17-27

8. Mimura T, Mimura Y, Arimoto A, Amano S, et al. Relationship between refraction and allergic conjunctivitis. Eye (2009) 23, $63-66$.

9. Ayanniyi AA, Adepoju FG, Ayanniyi RO, Morgan RE. Challenges, attitudes and practice of spectacle wearers in a resource-limited economy. Middle East Journal of Ophthalmology 17 (1):83-87.

10. Pesudovs K, Elliott DB. Refractive error changes in cortical, nuclear, and posterior subcapsular cataracts. $\mathrm{Br}$ JOphthalmol 2003 August; 87(8):964 - 967.

11. Ramakrishnan R, Nirmalan PK, Krishnadas R, Thulasiraj $\mathrm{RD}$, Tielsch JM, Katz J, et al. Glaucoma in a rural population of southern India: The Aravind Comprehensive Survey. Ophthalmology. 2003; 110: 1484-90.

12. Venkatasw amy G, Lepkow ski JM, Ravilla T, Brilliant GE, Shanmugham CA, Vaidyanathan K, et al. Rapid epidemiologic assessment of cataract blindness. The Aravind Rapid Epidemiologic Assessment Staff. Int $J$ Epidemiol. 1989; 18:S60-7. 
13. Raizada IN, Mathur A, Narang SK. A study of prevalence and risk factors of senile cataract in rural areas of w estern UP. Indian JOphthalmol. 1984; 32:339-42.

14. Bachani D, Murthy GV, Gupta KS. Rapid assessment of cataract blindness in India. Indian J Public Health 2000; 44:82-9.

15. Chatterjee A, Milton RC, Thyle S. Prevalence and aetiology of cataract in Punjab. Br J Ophthalmol 1982; 66:35-42.

16. Nirmalan PK, Krishnadas R, Ramakrishnan R, Thulasiraj $\mathrm{RD}$, Katz J, Tielsch JM, et al. Lens opacities in a rural population of southern India: The Aravind Comprehensive Eye Study. Invest Ophthalmol Vis Sci. 2003; 44:4639-43.

17. Loew enthal R, Pe'er J. A prevalence survey of ophthalmic diseases among the Turkana tribe in north-west Kenya. $\mathrm{Br}$ JOphthalmol. 1990; 74:84-8.

18. McCarty CA, Mukesh BN, Fu CL, Taylor HR. The epidemiology of cataract in Australia. Am JOphthalmol. 1999; 128:446-65.

19. Leske MC, Connell AM, Wu SY, Hyman L, Schachat A. Prevalence of lens opacities in the Barbados Eye Study. Arch Ophthalmol 1997; 115:105-11.
20. Singh MM, Murthy GV, Venkatraman R, Rao SP, Nayar S. A study of ocular morbidity among eld erly population in a rural area of central India. Indian J Ophthalmol 1997; 45:61-5.

21. Jacob A, Thomas R, Koshi SP, Braganza A, Muliyil J. Prevalence of primary glaucoma in an urban south Indian population. Indian JOphthalmol 1998; 46:81-6.

22. Awasthi P, Sarbhai KP, Banerjee SC, Maheshwari BB. Prevalence study of glaucoma in rural areas. Indian $J$ Ophthalmol 1975; 23:1-5.

23. Singh MM, Murthy GV, Venkatraman R, Rao SP, Nayar S. A study of ocular morbidity among eld erly population in a rural area of central India. Indian J Ophthalmol 1997; 45:61-5.

24. Adegbehingbe BO, Majemgbasan TO. Ocular health status of rural dwellers in south-western Nigeria. Aust JRural Health 2007; 15:269-272.

25. Buhrmann RR, Quigley HA, Barron Y, West SK, Oliva MS, Mmbaga BB. Prevalence of glaucoma in a rural East African population. Invest Ophthalmol and Vis Sci 2001;41: 40-48. 